\title{
The Work of Attracting Vietnamese Intellectuals Abroad in the Innovate Period in Vietnam
}

\author{
Dr. Nguyen Thi Hong Mai ${ }^{1}$, Dr. Mai Quoc Dung ${ }^{2 *}$ \\ ${ }^{1}$ Ho Chi Minh National Academy of Politics, Vietnam \\ ${ }^{2}$ Ho Chi Minh City University of Food Industry, Vietnam \\ *Corresponding Author
}

\begin{abstract}
Inheriting and promoting the long and fine tradition of the nation that considers "genius as the national spirit", Vietnam has adopted appropriate guidelines and policies to gather, unite, build and develop strongly promote the role of intellectuals, including Vietnamese intellectuals abroad, creating conditions and motivation for them to freely research, create and contribute. The results achieved in the work of attracting and promoting the resources of Vietnamese intellectuals abroad in the past time have confirmed the right direction of Vietnam, but there are still limitations barrier. That situation needs to be frankly recognized, in order to set out appropriate policies, further promote the achieved results, and overcome limitations and barriers.
\end{abstract}

Keywords: Attraction, innovate, intellectuals, Overseas Vietnamese, resources.

\section{INTRODUCE}

$\mathrm{O}$ verseas Vietnamese intellectuals are an important resource of the nation. In recent years, Overseas Vietnamese intellectuals have made practical contributions to the country. Since the beginning of the country's renovation (1986), the Communist Party of Vietnam, as the ruling party in Vietnam, has had many policies to promote the role of Vietnamese intellectuals abroad. However, the contribution and dedication of Vietnamese intellectuals abroad are still limited compared to their potential and the requirements of the industrialization and modernization of the country.

In order to attract talents, promote the contributions and dedication of overseas intellectuals to the construction and development of the country, the Government and the ministries, branches and localities in the country need to continue to perfect and building a new policy system as well as the affection, goodwill and efforts from the overseas Vietnamese intellectuals. Research on the overseas Vietnamese intellectual community and the actual implementation of policies to attract overseas Vietnamese from which to make recommendations to improve policies and effectively attract resources from overseas Vietnamese overseas intellectuals is an issue that needs to be further studied, valuable in both theory and practice.

Research question:

Question 1: What is the potential of Vietnamese intellectuals abroad?
Question 2: What can overseas Vietnamese intellectuals contribute to the development of Vietnam?

Question 3: What policy does Vietnam have to promote the potential of Vietnamese intellectuals abroad?

Question 4: What will Vietnam have to do to promote the potential of overseas Vietnamese intellectuals in the near future?

\section{Some characteristics of Vietnamese Intellectuals abroad}

Assessing the ability to make the biggest and most important contribution of overseas Vietnamese to the cause of industrialization and modernization of the country is first and foremost the brain, not the economy. Gray matter for scientific knowledge and gray matter for modern management knowledge, Vietnam is in dire need. With more than 500,000 overseas Vietnamese with university and post-graduate degrees, although this number is slightly off from reality, it must be affirmed that this is a great and valuable potential. It should be noted, this is the "updated" gray matter, the "diverse" gray matter trained from world-renowned universities and scientific research centers with many different professions, some of jobs in supranational companies, large international organizations and thus have the opportunity to grasp the knowledge of the latest knowledge of human intelligence, the latest information of the times.

General overview: Compared with other ethnic minority communities, the Vietnamese community in general and overseas Vietnamese intellectuals in particular abroad are young, dynamic, quickly integrated and the majority Some tend to settle in the host country for a long time, mainly the US, Australia, Canada and Western European countries (about $80 \%$ have naturalized in the country of residence but most have not given up Vietnamese nationality), while the majority Vietnamese people in Russia and Eastern Europe still consider life as temporary residence and will return home when conditions permit. However, the overseas Vietnamese community is a complex community in terms of social composition, political trends, and diversity in occupations, religions, and ethnicities. Differences in class, political opinion and circumstances of leaving as well as residing in different areas. Therefore, the connection and attachment in the community is not high. The community is scattered, 
community activities are difficult, maintaining the Vietnamese language and preserving the traditional national cultural identity is a big challenge for the future of the community.

About the number of Vietnamese intellectuals abroad: Out of more than 5,000,000 overseas Vietnamese, there are about 500,000 highly qualified people, according to incomplete statistics of developed countries with large numbers of Vietnamese: the US, Australia, France (Linh K, $2020) \ldots$ in which, about 6,000 people have doctorate degrees (compared to about $16,000 \mathrm{PhDs}$ living and working in the country, the ratio of doctorates per capita of the community is overseas Vietnamese is $2 / 1000$, about 10 times higher than domestic). In the US alone, $30 \%$ have university degrees, more than $10 \%$ have master's degrees or higher, and in Silicon Valley, there are about 10,000 to 12,000 Vietnamese people working.

In terms of qualifications and employment characteristics: Highly qualified people are basically trained at university, post-university level and high-level technical workers, have up-to-date knowledge of culture, science and technology, economic management, and state management. There are many people who have achieved important positions in research institutes, universities, hospitals, business companies and international organizations, there are even people who work and hold high positions in the industry government in the host country.

Regarding attitudes and ideas towards the homeland and the country: There is a part of expatriates who do not properly understand the situation of the country, so they still have a negative or reserved attitude towards the country, even a few For those who go against the common interests of the nation. The majority of the community always maintains a close relationship with their homeland, wishing for the country's rapid development and international integration.

Regarding the specificity of labor and creativity of Vietnamese intellectuals abroad: The common characteristic of creative labor of the intellectual team is intellectual and creative work. This is the special resource of each country. The special feature of brain resources is that if they know how to exploit them, their socio-economic benefits will be enormous, but if they don't know how to promote them, this resource will be gradually worn out even lost over time. Besides, intellectuals have high self-esteem, but are always willing to devote their talents to the development of the country.

About the ability to contribute to the country: Through practice, Vietnamese intellectuals abroad today can actively contribute to the development of the country through the following channels: Planning consultancy national development policies, economic sectors, sciences technology, education - training and implementation solutions. Directly participating in or supporting scientific research and technology development, knowledge transfer, technology transfer, advanced management experience for socio-economic development and national defense. Participating in education and training activities for qualified human resources to meet the requirements of the country. Acting as a bridge for cooperation activities in science technology, education and training, between domestic and foreign scientists. Provide up-to-date information for industries and sectors of the economy. Looking for investment sources, or participating in direct investment in economic development, science - technology, education - training...

The potential and dedication of Vietnamese intellectuals abroad is obviously huge and needs to be opened up, so that that flow can contribute to the construction of the homeland and the country. Create a push in the fields of economy, science and technology as well as in the fields of culture, ideology and state management. Therefore, the promulgated policies must be strong enough to create a specific and attractive remuneration framework for living, working and studying conditions for overseas Vietnamese intellectuals and their families and children when they return home to work.

\section{THE WORK OF ATTRACTING OVERSEAS VIETNAMESE INTELLECTUALS}

The issue of overseas Vietnamese in general and overseas Vietnamese intellectuals in particular is a big issue, which is always concerned by the Vietnamese State, which always identifies overseas Vietnamese as flesh and blood, a resource of the people ethnicity. It is that consistent point of view that has attracted the contribution of overseas Vietnamese to the cause of national defense and construction. Especially since 1986, when our Vietnam started implementing the policy of renewal and opening up, overseas Vietnamese intellectuals have strengthened their relationships and cooperation with the country. Vietnam's innovate process has achieved many important achievements that have increased the confidence of overseas intellectuals in the development of the country and the future of the nation, thus continuing to attract more and more people many people in the intelligentsia are attached to the country.

An important turning point for overseas Vietnamese work was when for the first time there was a separate Resolution on this work, which was Resolution No. 08NQ/TW dated November 29, 1993 of the Communist Party of Vietnam south on Policies and work for overseas Vietnamese, the Resolution identifies: The potential of the overseas Vietnamese community, especially in science and technology, in terms of capital, and the ability to create relationships between organizations and individuals abroad with in the country is an advantage and an important resource that needs to be promoted to supplement and support the development of the country, from which the Resolution sets forth major policies and measures as follows: Encouraging and facilitating easy for expatriates to transfer knowledge, technology and 
advanced management experience to the country (Communist Party of Vietnam, 1993).

Based on the results of 10 years of implementing Resolution No. 08-NQ/TW, for the first time, a public Resolution on this work was Resolution No. 36-NQ/TW dated March 26, 2004 of the Party Communist Vietnam on Working with overseas Vietnamese, the Resolution stated the following main tasks: Completing and building a new system of policies to attract and utilize talents and promote contributions of overseas intellectuals in the development of the country. Develop a satisfactory treatment regime for overseas Vietnamese experts and intellectuals who have high professional qualifications and are capable of consulting on management, administration, technology transfer, and high technology in the field of science and technology, contributing to the development of the country's culture and art; Formulate and perfect policies to facilitate and encourage branches, science and technology research centers, culture and arts, education and training, health care, physical training and sports facilities production and service establishments... in the country to expand cooperation, attract the use of overseas Vietnamese experts and intellectuals to work in the country, work for programs and projects in cooperation Vietnam's multilateral and bilateral cooperation with foreign countries or in international organizations with quotas for Vietnamese people and consulting in relations between Vietnam and foreign partners (Communist Party of Vietnam, 2004).

Resolution No. 27-NQ/TW dated August 6, 2008 of the Communist Party of Vietnam on Building a contingent of intellectuals in the period of accelerating industrialization and modernization of the country, continuing to reaffirm the Vietnam's right policy and propose solutions to implement in the new context, including solutions to attract and promote the role of Vietnamese intellectuals abroad, the Resolution affirmed: Vietnamese intellectuals Men come from many classes and social classes, especially from workers and farmers; Most of them have grown up in the new society, formed from many training sources at home and abroad, with many successive generations, including a part of overseas Vietnamese intellectuals... The majority of Vietnamese intellectuals abroad always look to the Fatherland; Many people have returned home to work and operate in different fields, making practical contributions to the development of the country. From such positions and roles, the Resolution sets out the following tasks: To develop policies to attract and gather Vietnamese intellectuals at home and abroad to actively participate in planning, cooperation in training, scientific research, etc. transfer of new technologies... Appreciate and honor intellectuals who have made practical and effective contributions to the cause of industrialization and modernization of the country and international integration (Communist Party of Vietnam, 2008).

On May 19, 2015, the Communist Party of Vietnam issued Directive No. 45-CT/TW on Continuing to promote the implementation of Resolution No. 36-NQ/TW of the IX Politburo on the work of overseas Vietnamese in the new situation, the Directive stated tasks and solutions: Reviewing, supplementing and perfecting mechanisms, policies and laws to create a favorable legal corridor for overseas Vietnamese on investment, production and business, contributing to attracting investment, transferring technology from other countries to Vietnam and promoting exports and supporting Vietnam's investment abroad. To adopt policies to attract and employ overseas Vietnamese experts and intellectuals, especially in essential fields, to meet the requirements of the cause of national construction and defense (Communist Party of Vietnam, 2015).

Concretizing guidelines and policies, the Government of Vietnam has issued action programs and implementation Decrees. In particular, Decree No. 87/2014/ND-CP dated September 22, 2014 of the Government stipulating on "Attracting individuals in scientific and technological activities who are overseas Vietnamese and foreign experts to participate in scientific and technological activities in Vietnam", this is the first Decree of the Government directly related to the work of attracting Vietnamese intellectuals abroad. The Decree has stated specific main attractions such as: Policies on immigration and residence; policies on recruitment, labor and learning; Wage policy; housing policy; policy on access to information; policy on reward, honor and some other policies. The policies have basically mentioned the issues that Vietnamese intellectuals abroad aspire to, creating an important legal corridor for localities and agencies to boldly set out plans to attract overseas Vietnamese intellectuals according to the law practical needs.

From the guidelines and policies of Vietnam every year, more than 300 turns of Vietnamese intellectuals abroad such as the USA, France, the Federal Republic of Germany, Japan and Australia return to Vietnam to work with ministries, sectors and localities, scientific research institutions or product production and processing facilities, including a number of people who have been invited to work as consultants to the Prime Minister. Some fields of research and effective cooperation include informatics and informatics applications, electronics, telecommunications, medicine, composite materials, education-training, finance-accounting, banking, construction, printing technology, food processing and preservation, plant varieties, aquaculture, industrial waste treatment... From 2015 up to now, many conferences and forums have also been organized such as: Forum of Vietnamese experts and intellectuals abroad with Vietnam's economic development and integration in the 2016-2020 period. Annual Meeting of Vietnamese Economists VEAM 2017, Vietnam Innovation Networking Program 2018 to contribute ideas in developing Vietnam's strategy to adapt to the changes of the Revolution Industry 4.0, in collaboration with the Association of Vietnamese Scientists and Experts Global (AVSE Global) to organize the Influential Vietnamese 
Forum to be held in 2019, the Conference "Overseas citizens contribute ideas on digital transformation and overcome the impact of the Covid-19 pandemic to develop Vietnam's economy" held in 2020 (Linh K, 2020).

The Vietnam Innovation Networking Program took place in August 2018 organized by the Ministry of Planning and Investment in collaboration with the Ministry of Science and Technology, the Ministry of Foreign Affairs, the Ministry of Education and Training. The Vietnam Innovation Network was launched and gathered more than 100 typical experts and scientists, operating in the fields of information technology, biology, artificial intelligence technology, internet of things... in Vietnam south and abroad.

The Network's activities aim to gather and gather Vietnamese intellectuals, and connect science and technology activities; support and connection between corporations, investment funds, domestic start-ups wishing to develop business activities abroad; connect with universities, research institutes, laboratories, experts in host countries to cooperate in training, provide scholarships, support excellent students and students of Vietnam to study and study abroad. research in that country... towards the goal of building and gathering high-quality human resources ready to participate in the country's innovative activities.

Along with that, the National Innovation Center (under the Ministry of Planning and Investment) is tasked with operating and developing the Vietnam Innovation Network, including young intellectuals and scientists currently working and researching for domestic and foreign agencies, organizations and corporations, in accordance with the spirit of Resolution No. 52-NQ/TW dated September 27, 2019 of the Communist Party of Vietnam on a number of policies, policy to actively participate in the Fourth Industrial Revolution. Up to now, the Network has connected more than 300 members in 14 countries to deploy and build component networks in the United States, Korea, Germany, Australia, and Japan (Diep T, 2020).

However, in reality, the mobilization of the brains of overseas intellectuals is still spontaneous and fragmented, just stopping at inviting scientists to return home to work as consultants for a number of projects, to participate in teaching at universities. The mobilization of high-caliber overseas scientists to participate in the priority areas of the country has not done much yet. Many Vietnamese intellectuals abroad wish to contribute their intellect and enthusiasm to the country, but they do not know what domestic needs and how to contribute, while they are bound by financial constraints. Meanwhile, the domestic authorities have not yet issued longterm plans, specific requirements as well as adequate measures and policies to take advantage of the contribution of brains of overseas intellectuals. More importantly, there is still a lack of an open mechanism for overseas intellectuals to have more opportunities to work and develop and contribute their wisdom to the country. The summarization and statistics of the work of attracting Vietnamese intellectuals abroad are still limited, even the exact number of overseas Vietnamese intellectuals returning home is not available, the figures are only estimates.

\section{LIMITATION CAUSES}

Firstly, there is currently a lack of an open database capable of connecting the Vietnamese intellectual community network in the world, both updating individual profiles and sharing information, and becoming a forum strengthens the connection of Vietnamese intellectuals at home and abroad. This is not only a database, but also a network that coordinates as well as activities to enhance the effectiveness of its members. This is especially necessary because at present, the Vietnam is in dire need of knowledge and experience of good experts to cooperate in developing a number of priority high-tech fields such as nuclear power technology, space, automation,...

Second, ministries, branches, localities, universities and research institutes all have the need to attract overseas intellectual experts to cooperate and work, but there are no feasible programs and projects; The role of new intellectuals is mentioned in general on many documents and papers, the results of conferences and seminars have not been implemented in reality or the recommendations of expatriates have not been resolved. Ministries, branches and localities have not identified the need to use as well as lack of information about Vietnamese intellectuals abroad, so it is very difficult to consult and use...

Third, it is clear that the application of scientific research works is still less effective, the promotion and payment of salaries for researchers is not really worth it, etc. are also obstacles, is an unattractive point for Vietnamese experts and intellectuals abroad.

Fourth, in scientific activities, differences in thinking and working styles, etc are also significant barriers to joint cooperation programs. The role of overseas Vietnamese intellectuals in universities and research institutes has not been promoted. In addition, the lack of research facilities such as laboratories, international contacts, strong working teams... are also considered significant difficulties. In addition, obstacles in funding consideration and granting for scientific and technological research activities in general and the lack of specific treatment regimes for overseas intellectuals have been and are major obstacles for foreign nationals the mobilization of overseas Vietnamese experts and intellectuals to return home to work.

The intellectual potential of the expatriates is very large, which is considered a strength of the community, but there is almost no effective exploitation policy. Therefore, in order to build a strong group of intellectuals, it is necessary to pay more attention to the State Vietnam, especially to build a breakthrough "special" mechanism to attract more resources both economic and brainpower of expatriate experts and 
intellectuals. It is necessary to determine the criteria for selecting and attracting talented people, developing screening criteria and regulations to select the best individuals in the overseas Vietnamese community as well as developing support policies finance for them. On the other hand, the State also needs to set aside a budget to prioritize investment in the development of scientific research institutions, properly invest in education and training, and focus on developing highly qualified human resources. It is necessary to take measures for the issued policies to be effectively implemented: creating favorable conditions for overseas Vietnamese to buy houses, eliminating unnecessary administrative procedures, implementing the "one-stop shop mechanism" In handling administrative procedures for overseas Vietnamese, amending and supplementing a number of regulations on recruiting overseas intellectuals into management positions at domestic agencies.

\section{Some recommendations to improve the efficiency of attracting} Vietnamese intellectuals abroad

Continuing the cause of innovation, model building and socio-economic development, taking the foundation of the knowledge economy as a goal, the driving force for deep integration needs more intellectual contributions from intellectuals . Therefore, the knowledge of the nation and of humanity needs to be consulted in a rigorous, serious and sincere way. With invaluable "resources" from overseas Vietnamese intellectuals, it will be a waste if not used, but if used appropriately, it will make an important contribution to the path we have choose to succeed. In that process, it is necessary to have a strong, synchronous solution reflected in the drastic policy of the policy, which is the key factor to create a strong and effective effect.

\section{Continue to innovate thinking, mechanisms and policies}

In the context of deep international integration, the effective use of overseas intellectual resources to solve the country's socio-economic development problems is an extremely important task. Continuing to implement the guiding spirit of Directive 45-CT/TW on working with overseas Vietnamese and developing the country in the new situation, over the years, the Government has reviewed and supplemented perfecting mechanisms, policies and laws, creating a favorable legal corridor for overseas Vietnamese to invest, produce and do business, contribute to attracting investment and technology transfer from other countries to Vietnam. South and promote exports, support Vietnam's investment abroad.

Need to continue to innovate thinking; detect knots; removing barriers, perfecting mechanisms and policies to create a truly favorable and healthy environment. At the same time, unleashing the creative potential of scientists, dramatically increasing the results and effectiveness of scientific and technological contributions to the country's long-term development goals.

\section{Build a database and form a working group}

Improving the efficiency of the network of overseas intellectual associations supporting innovation and technology commercialization by the Project 844 Office, Ministry of Science and Technology in collaboration with the State Committee for Overseas Vietnamese, the Vietnam Science and Technology Enterprise Startup Fund. The establishment of the Network will help promote the intellectual connection of Vietnamese experts and intellectuals abroad, optimize resources to promote innovation and start-ups in the country. Network orientation in two main contents: One is full and upto-date information about the innovation ecosystem and startups in Vietnam to the overseas Vietnamese intellectual community. In the opposite direction, information about the strengths of overseas experts and intellectuals is also gathered and published to target potential joint activities. Create conditions so that the knowledge, knowledge and technology of overseas Vietnamese will be brought back to the country for socio-economic development.

The establishment of groups working on each issue needs to be done professionally and oriented, in addition to current issues of focus such as education - training, science technology, and economics, culture, etc., political and policy issues have not received much attention. The Vietnamese intellectuals abroad themselves are having a lot of worries, thoughts and discussions about this issue, but it is mainly spontaneous, sporadic, and lacks orientation. Therefore, a group of political and policy research activities established and sponsored by the State will gather the number and orientation of activities, topics, research topics, and discussions in accordance with the law. suit the needs of the country.

Boldly order Vietnamese intellectuals abroad to study specific issues

The 13th National Congress of the Communist Party of Vietnam (in 2021) identifies 6 focuses, 3 strategic breakthroughs and 12 key tasks, requiring the entire Vietnamese political system to have awareness new and scientific thinking. Associate with practical and effective solutions to put the Party's guidelines and lines into practice, especially making science and technology a driving force for development, contributing to the rapid and sustainable development of the country. Therefore, must always trust the team of Vietnamese intellectuals in general and overseas Vietnamese in particular, boldly place orders and assign them to research groups, overseas Vietnamese associations, experts to carry out consultancy, social criticism and assessment of many large, difficult and interdisciplinary projects, especially those on important guidelines, guidelines and policies of the Party and Government; major national programs, projects and works.

Requires agencies, sectors and localities to also pay more attention to science and technology development, listen 
to critical opinions of scientists. The more difficult, complex and sensitive issues are, the more they must maintain their bravery, uphold principles, promote democracy, mobilize collective wisdom, and listen to each other's opinions, including opinions. Consider and decide, especially new and breakthrough issues, all for the benefit of the nation, the nation, and the people.

\section{CONCLUDE}

The State of Vietnam has affirmed that overseas Vietnamese are a part and resource of the country and requires both the political system and the entire people to be responsible, in combination with the synchronous construction of mechanisms, policy and advocacy work, combining domestic and foreign activities, by various forms and measures suitable to different audiences and locations. However, so far, there are still too few policies to attract and create an environment and conditions for overseas intellectuals to contribute to the construction of the country. Many levels of government have not really paid attention to attracting and facilitating, inviting experts, and have not identified specific cooperation needs. Most of the places that have been implementing cooperation programs with Vietnamese intellectuals abroad still only provide information on short-term teaching, exchange and discussion, etc. Ministries and sectors The locality has not yet built up specific and practical mechanisms as well as appropriate funds to attract overseas Vietnamese experts and intellectuals. Vietnam needs to develop synchronous mechanisms, policies, and solutions from micro to macro levels, increase awareness and coordination among sectors and levels to create a strong transition and energize the country overseas Vietnamese in general and overseas Vietnamese intellectuals in particular, towards the country, actively participate in contributing to the construction of the homeland.

\section{Issues that need further research:}

Firstly: Comprehensively study the global and regional scope of the potential of overseas Vietnamese intellectuals;

Second: Clearly define the fields that overseas Vietnamese intellectuals can contribute to Vietnam;

Third: Review policies for overseas Vietnamese intellectuals to add or remove inappropriate policies;

Fourthly: Summarizing the implementation of the policy of attracting Vietnamese intellectuals abroad, clearly stating the advantages, limitations and reasons for a more comprehensive and appropriate solution.

\section{REFERENCES}

[1] Communist Party of Vietnam (1993). Resolution No. 08 NQ/TW on the Work of mobilizing overseas Vietnamese.

[2] Communist Party of Vietnam (2004). Resolution No. 36-NQ/TW on Working with overseas Vietnamese.
[3] Communist Party of Vietnam (2008). Resolution No. 27-NQ/TW on Building a contingent of intellectuals in the period of accelerating industrialization and modernization of the country.

[4] Communist Party of Vietnam (2015). Directive No. 45-CT/TW on Continuing to accelerate the implementation of Resolution No. 36 of the IX Politburo on work with overseas Vietnamese in the current situation new.

[5] Communist Party of Vietnam (2019). Resolution No. 52-NQ/TW on a number of Undertakings and policies to actively participate in the Fourth Industrial Revolution.

[6] Dan T.T.D. (1997). Overseas Vietnamese, National Political Publishing House, Hanoi.

[7] Diep T. (2020). 5 years of implementing Directive 45-CT/TW: Attracting overseas intellectual resources, https://baotintuc.vn/thoi-su/5-nam-thuc-hien-chi-thi $-45 \mathrm{cttw}-$ thuhut-nguon-luc-tri-thuc-kieu-bao-20201127102649373.htm

[8] Dung M.Q. (2018). Overseas Vietnamese are an integral part and resource of the Vietnamese ethnic community, Journal of Education and Society, pp. 85-88

[9] Dung M.Q. (2021). Promoting the intellectual resources of overseas Vietnamese in the process of building a Constructive Government, Journal of Political Theory, pp. 81-85.

[10] Government of Vietnam (2014). Decree No. 87/2014/ND-CP Regulating the attraction of individuals in science and technology activities who are overseas Vietnamese and foreign experts to participate in scientific activities and technology in Vietnam.

[11] Government of Vietnam (2020). Decree No. 27/2020/ND-CP in which amending and supplementing a number of articles of the Government's Decree No. 87/2014/ND-CP on attracting individuals to work science and technology activities are overseas Vietnamese and foreign experts participating in science and technology activities in Vietnam.

[12] Linh K. (2020). Promoting work for overseas Vietnamese in the new situation, https://dangcongsan.vn/nguoi-viet-nam-o-nuocngoai/day-manh-cong-tac-doi-voi-nguoi-viet-nam-o-nuoc-ngoaitrong-tinh-hinh-moi-568517.html

[13] Ngoc D. (2020). "5 things missing" in attracting overseas intellectuals, https://nld.com.vn/thoi-su/5-cai-thieu-trong-thu-huttri-thuc-kieu -bao-20201127065348475.htm

[14] Thang V. (2020). Attracting overseas intellectuals in "key spear" fields, http://daidoanket.vn/thu-hut-tri-thuc-kieu-bao-o-cac-linhvuc- mui-nhon-525085.html

[15] Vui T.T. (2017). Policy of the Party and State towards overseas Vietnamese in the innovate period, Political Theory Publishing House. 